CLINICAL STUDY

\title{
Differences and similarities regarding adiponectin investigated in African and Caucasian women
}

\author{
Aletta E Schutte, Hugo W Huisman, Rudolph Schutte, Leoné Malan, Johannes M van Rooyen, Nico T Malan \\ and Peter E H Schwarz ${ }^{1}$ \\ School for Physiology, Nutrition and Consumer Sciences, North-West University (Potchefstroom Campus), Private Bag X6001, Potchefstroom 2520, \\ South Africa and ${ }^{1}$ Technische Universität Dresden, Medizinische Fakultät Carl Gustav Carus, Fetscher str. 74, 01307 Dresden, Germany \\ (Correspondence should be addressed to A E Schutte; Email: alta.schutte@nwu.ac.za)
}

\begin{abstract}
Objective: Concentrations of adiponectin, an adipocytokine with insulin-sensitizing actions, may vary according to ethnic group. This study aimed to determine whether fasting adiponectin levels of Caucasian and African women differ. A second objective was to determine which components of the metabolic syndrome are more closely related to adiponectinemia in both groups.

Design: A cross-sectional study including 102 urban African and 115 Caucasian women with a wide range of obesity aged 20-55 years.

Methods: Anthropometric measurements were taken, namely weight, height, body mass index, waist circumference, and hip circumference. Cardiovascular measurements included blood pressure and arterial compliance. Fasting blood samples were taken to determine glucose, insulin, C-peptide, leptin, adiponectin, and lipid levels.

Results: Mean adiponectin levels of the whole groups did not differ, but normal weight African women $(N=38)$ showed marginally lower adiponectin levels than their Caucasian counterparts $(N=41$; $P=0.047)$. No differences in adiponectin were shown for overweight and obese women. Separate multiple regression analyses for ethnic groups showed that only homeostasis model assessment-insulin resistance (HOMA-IR) significantly contributed to the variance in adiponectin levels of African women, whereas leptin, triacylglycerol levels and HOMA-IR contributed significantly to adiponectin variance in Caucasian women. An additional multiple regression analysis in a combined ethnic group $(N=217)$ showed ethnicity to be a significant contributor to variances in adiponectin levels.

Conclusions: Even though adiponectin levels of these ethnic groups are similar, different associations of adiponectin with leptin and triacylglycerol levels might indicate that there are ethnic differences regarding the mechanistic functions of adiponectin within the scope of the metabolic syndrome.
\end{abstract}

European Journal of Endocrinology 157 181-188

\section{Introduction}

Alarmingly high prevalence levels of the metabolic syndrome and type 2 diabetes in developed and developing countries are forcing scientists to review promising therapeutic agents. One of these agents is adiponectin, which is a novel peptide abundantly expressed in adipose tissue (1). What makes this adipocytokine so attractive is its recently discovered anti-atherogenic $(2,3)$, anti-diabetic $(4,5)$, and antiinflammatory $(6,7)$ properties. In contrast to other adipocytokines, adiponectin levels are inversely related to visceral fat area, and low levels have been associated with obesity, type 2 diabetes, and cardiovascular disease (8-11).

Low plasma levels of adiponectin characterize both obesity and insulin resistance (IR) (7). Even though negative correlations have been found between adiponectin and obesity $(8,11)$, it has been suggested that plasma adiponectin concentrations are more closely related to insulin sensitivity and fasting insulinemia than to adiposity and glycemia, and that factors other than adiposity must play a role in determining adiponectinemia $(10,12)$. However, few studies have investigated whether this is true within different population groups, especially because of contradictory results regarding adiponectin levels and age, and adiponectin gender differences have been reported for Pima Indians $(8,13)$ compared with other population groups $(8,14)$.

Comparative studies of adiponectinemia in populations with different propensities for obesity, IR, type 2 diabetes, and atherosclerosis are warranted (10). Hulver et al. (15) published one of only a few studies examining ethnic differences in adiponectin levels. They found significantly lower adiponectin levels in normal weight African-American women compared with normal weight Caucasian women, with no difference 
between obese groups (15). Weyer et al. (10) performed a comparative study between Caucasians and Pima Indians and found significantly lower levels of adiponectin in Pima Indians. It has been suggested that the association between adiponectin and insulin sensitivity may be race specific (15).

Literature is limited regarding the metabolic health status of Africans. It is also unknown whether the results on African-Americans hold true for South Africans (16, 17). The South African Demographic and Health Survey (18) described high rates of obesity, with women showing the highest levels for being obese or overweight (56\%). The survey concluded that the predominant pattern of malnutrition in adult South Africans, particularly African women, is one of over-nutrition resulting in remarkably high rates of obesity. It is therefore clear that South Africa is in line with a number of other developing countries and faces a growing challenge in confronting the epidemic of type 2 diabetes mellitus that is likely to develop over the next few decades.

The aim of this study was to determine whether Caucasian and African women from South Africa differ regarding fasting adiponectin levels. A second objective was to determine which metabolic syndrome-related components (hyperinsulinemia, IR, obesity, dyslipidemia, and hyperleptinemia) are more closely related to adiponectinemia in both ethnic groups. This might provide more insight regarding the mechanistic functions of adiponectin, and whether this is similar for both African and Caucasian women.

\section{Methods}

\section{Study design and subject selection}

The study formed part of the Profiles of Obese Women with the Insulin Resistance Syndrome (POWIRS) study which involved 102 apparently healthy urban African women (working at a government institution in Potchefstroom) and 115 Caucasian women (working in Potchefstroom) from the North West Province, South Africa. More detail regarding the methods of the full study have been described elsewhere (18), but all relevant information for the present study is provided below. The inclusion criteria were apparently healthy women aged between 20 and 55 years. Since body mass index (BMI) effectively predicts body fat percentage (19), subjects were recruited based on their BMI. Three groups of subjects were selected based on guidelines in the Report of the World Health Organization Consultation on Obesity (20), being i) normal range (lean) with BMI: $18.5-24.9 \mathrm{~kg} / \mathrm{m}^{2}$; ii) overweight (pre-obese) with BMI: $25-29.9 \mathrm{~kg} / \mathrm{m}^{2}$; and iii) obese with BMI $\geq 30 \mathrm{~kg} /$ $\mathrm{m}^{2}$. Pregnant and lactating women and those with oral temperatures above $37^{\circ} \mathrm{C}$ were excluded.

\section{Ethical considerations}

The study was approved by the Ethics Committee of the North-West University and the procedures followed were in accordance with the Helsinki Declaration of 1975, as revised in 2000. All subjects were fully informed about the objectives and procedures of the study prior to their inclusion, and assistance was available to provide information in their home language. All subjects signed an informed consent form.

\section{Organizational procedures}

After arrival at a Metabolic Unit Facility, subjects were introduced to the setup and after the experimental procedures were explained to them, they voluntarily signed informed consent forms. Each subject received a 'participant sheet' which guided them through the different research 'stations' where the various measurements were done. During the course of the evening, demographic questionnaires were filled in and anthropometric measurements were taken. All participants received a similar light supper which excluded alcohol and caffeine at $2000 \mathrm{~h}$ and went to sleep before $2300 \mathrm{~h}$, thus fasting overnight. From $0600 \mathrm{~h}$ in the morning, blood pressure measurements were taken. Afterwards a fasting blood sample was taken.

\section{Anthropometric measurements}

One experienced anthropometrist was responsible for all measurements of height (stature), weight, and waist and hip circumferences of subjects in their underwear with calibrated instruments (Precision Health Scale, A \& D Company, Japan; Invicta Stadiometer, IP 1465, UK; Holtain unstretchable metal tape, Crymych, UK; John Bull calipers, British Indicators, London, UK). Measurements were done using standard methods as described by Norton \& Olds (21). The researcher's measurements were standardized and were taken in triplicate.

\section{Cardiovascular measurements}

A 7-min continuous measurement of cardiovascular parameters using the Finometer device (FMS, Finapres Measurement Systems, Amsterdam; 20-22) was taken by a cardiovascular physiologist and analyzed with the Beatscope 1.1 (FMS, Amsterdam, The Netherlands) software program to obtain systolic (SBP) and diastolic blood pressure (DBP), as well as the Windkessel arterial compliance. In its simplest, two-element form, the Windkessel model describes the circulation in terms of parallel resistance and capacitance components. The resistance element corresponds to measured peripheral vascular resistance, while the capacitance element corresponds to the compliance of the arterial circulation (23).

The vascular unloading technique of Peñáz together with the Physiocal criteria of Wesseling provided 
reliable, non-invasive, and continuous estimates of blood pressure which are useable especially in comparative studies, as with this one $(20,24,25)$. Since the pressure waveform is available continuously, computations provide further information on the dynamics of the cardiovascular system, similar to intra-arterial measurements $(20,22,24,25)$.

\section{Blood, serum and plasma samples}

A fasting blood sample was drawn from the vena cephalica by an experienced research nurse using a sterile winged infusion set and syringes. Serum lipids, glucose, insulin, C-peptide, leptin, and adiponectin levels were measured later in the laboratory, but blood glucose was measured directly in the Metabolic Unit with an enzymatic method to screen for diabetes mellitus (LifeScan SureStep Blood Glucose Monitoring System, LifeScan Inc., Milputas CA 9535, 1995, USA). For preparation of serum, blood was allowed to clot in glass tubes, centrifuged at 3500 r.p.m. for $10 \mathrm{~min}$ (Universal 16, Hettich, Tuttlingen, Germany), and transferred to $1.5 \mathrm{ml}$ Eppendorff tubes. EDTA blood was prepared by transferring $5 \mathrm{ml}$ blood into EDTA glass tubes. All serum and plasma samples were immediately stored at $-80{ }^{\circ} \mathrm{C}$ in the laboratory.

IR was estimated by the homeostasis model assessment (HOMA-IR index) calculated as the product of fasting glucose and insulin, divided by 22.5 .

\section{Biochemical analyses}

Serum lipids were measured on a Vitros DT60 II Chemistry System with Vitros DT slides. Serum leptin was measured with ${ }^{125}$ I IRMA kit (Diagnostic Systems Laboratories Inc., Webster, TX, USA; Cat. No. DSL23100). Plasma glucose was measured with the hexokinase method (inter assay coefficient of variation (CV) 1.5\%). Analysis of insulin and C-peptide levels was performed by enzyme immunoassay (BioSource EUROPE S A Belgium; inter assay CV 7.5\%, no cross reactivity with human proinsulin). Adiponectin levels were determined with the Human Adiponectin ELISA kit (BioCat GmbH, Heidelberg, Germany). Adiponectin, insulin, C-peptide, and glucose analyses were performed at the Medical Faculty of the Technical University, Dresden, Germany.

\section{Statistical analysis}

A power analysis for the present study revealed that 35 subjects are needed per group to reveal significant differences in adiponectin levels (when taking an s.D. of $4.5 \mathrm{ng} / \mathrm{ml}$, and a physiological difference of $1.5 \mathrm{ng} / \mathrm{ml}$ between groups into account). All processed data were transferred to Microsoft Excel and further statistically analyzed by means of the software computer package
Statistica Version 7. Means and 95\% CVs were calculated. Data that were not normally distributed were logarithmically transformed, and these included: adiponectin, triacylglycerol, and leptin. Independent $t$-tests were performed to determine significant differences in physical and metabolic variables between African and Caucasian women. Pearson correlation coefficients were performed for each ethnic group between log adiponectin levels and other components of the metabolic syndrome. Multiple regression analyses were performed for each ethnic group with log adiponectin as the dependent variable, and metabolic variables as independent variables. BMI was included as marker of obesity within this list of independent variables also due to its suggested strong correlation with leptin levels. Significant interaction terms were determined by $2 \times 2$ ANOVAs between ethnicity and BMI, log triacylglycerol, log leptin, log adiponectin, and HOMA-IR. A multiple regression analysis was also performed in a combined ethnic group with ethnicity included in the independent variable list.

\section{Results}

Physical and metabolic characteristics of the participating African and Caucasian women are shown in Table 1. Even though the two groups had similar ages, BMIs and waist-to-hip ratios, the data show clearly that the Caucasian women were roughly $10 \mathrm{~cm}$ taller and $10 \mathrm{~kg}$ heavier than their African counterparts. The Caucasian women also had a significantly greater waist circumference (WC; $P=0.024$ ). The African women had higher blood pressure (SBP, $P=0.042$; DBP, $P<0.001)$ and leptin levels $(P=0.026)$, and lower Windkessel arterial compliance $(P<0.001)$ and triglyceride levels $(P<0.001)$ than the Caucasian women. There were no differences regarding their adiponectin levels $(P=0.52)$, and all other measures of hyperinsulinemia and IR were also similar.

When comparing adiponectin and leptin levels of the two ethnicities for each level of obesity (i.e. normal weight, overweight, and obese groups), the normal weight groups showed the most significant results (Table 2). The normal weight African women showed higher leptin $(P<0.001)$ and somewhat lower adiponectin levels $(P=0.047)$ than their Caucasian counterparts. The overweight African women had significantly higher leptin $(P=0.019)$ but similar adiponectin levels than the Caucasian women, whereas no differences were shown between the obese African and Caucasian women.

In order to investigate the direct associations between adiponectin and metabolic syndrome components, correlations were performed within each ethnic group (Table 3). Fasting adiponectin levels showed significant correlations with most components in both ethnic 
Table 1 Physical and metabolic characteristics of the study population (mean \pm S.D. (95\% confidence intervals)).

\begin{tabular}{|c|c|c|c|}
\hline & African women & Caucasian women & $P$ value \\
\hline Number of participants & 102 & 115 & \\
\hline Age (years) & $31.3 \pm 8.64(29.6-32.9)$ & $31.3 \pm 9.17(29.6-33.0)$ & 0.945 \\
\hline Weight $(\mathrm{kg})$ & $70.6 \pm 15.8(67.4-73.7)$ & $80.7 \pm 21.0(76.8-84.6)$ & $<0.001$ \\
\hline Height $(\mathrm{m})$ & $1.59 \pm 0.05(1.57-1.60)$ & $1.68 \pm 0.07(1.67-1.70)$ & $<0.001$ \\
\hline Body mass index $\left(\mathrm{kg} / \mathrm{m}^{2}\right)$ & $27.9 \pm 6.33(26.7-29.2)$ & $28.5 \pm 7.14(27.2-29.8)$ & 0.588 \\
\hline Waist circumference (cm) & $81.6 \pm 13.2(79.0-84.2)$ & $85.9 \pm 14.9(83.2-88.8)$ & 0.024 \\
\hline Waist-to-hip ratio & $0.76 \pm 0.07(0.75-0.78)$ & $0.77 \pm 0.06(0.76-0.78)$ & 0.530 \\
\hline Systolic blood pressure $(\mathrm{mmHg})$ & $130 \pm 19.6(126-134)$ & $125 \pm 11.7(123-128)$ & 0.042 \\
\hline Diastolic blood pressure $(\mathrm{mmHg})$ & $77.7 \pm 10.7(75.6-79.8)$ & $72.5 \pm 9.01(70.8-74.1)$ & $<0.001$ \\
\hline Windkessel compliance $(\mathrm{ml} / \mathrm{mmHg})$ & $1.85 \pm 0.32(1.79-1.91)$ & $2.29 \pm 0.41(2.21-2.36)$ & $<0.001$ \\
\hline High density lipoprotein $(\mathrm{mmol} / \mathrm{l})$ & $1.25 \pm 0.33(1.19-1.32)$ & $1.21 \pm 0.32(1.15-1.26)$ & 0.287 \\
\hline Triacylglycerol (mmol/l) & $0.72 \pm 0.42(0.63-0.80)$ & $1.28 \pm 0.70(1.15-1.41)$ & $<0.001$ \\
\hline Fasting leptin (ng/ml) & $57.6 \pm 30.2(51.6-63.6)$ & $51.4 \pm 32.9(45.3-57.5)$ & 0.026 \\
\hline Fasting adiponectin (ng/ml) & $10.9 \pm 5.31(9.91-12.0)$ & $11.1 \pm 4.31(10.3-11.9)$ & 0.517 \\
\hline Fasting glucose $(\mathrm{mmol} / \mathrm{l})$ & $5.09 \pm 0.64(4.96-5.21)$ & $5.04 \pm 0.41(4.96-5.12)$ & 0.521 \\
\hline Fasting insulin (pmol/l) & $90.7 \pm 34.6(83.8-97.5)$ & $92.7 \pm 33.5(86.4-98.9)$ & 0.667 \\
\hline Fasting C-peptide (pmol/l) & $1232 \pm 629(1108-1357)$ & $1200 \pm 551(1097-1304)$ & 0.693 \\
\hline HOMA-IR & $3.01 \pm 1.38(2.73-3.28)$ & $3.04 \pm 1.29(2.80-3.28)$ & 0.882 \\
\hline
\end{tabular}

HOMA-IR, homeostasis model assessment-insulin resistance.

groups. These included inverse correlations with age (African women only), obesity (BMI, WC), triacylglycerol, leptin, fasting glucose, insulin, C-peptide, and IR (HOMA-IR). Neither ethnic group showed a significant correlation with SBP, whereas both correlated negatively with DBP. Only the Caucasian women showed a significant negative correlation with arterial compliance. Adiponectin levels of both groups correlated positively with high density lipoprotein levels.

Multiple regression analyses were performed separately for each ethnic group, with log adiponectin as the dependent variable (shown in Table 4). Independent variables included in this model were age, one measure for obesity (BMI), one measure for lipid metabolism (log triacylglycerol), one measure for IR (HOMA-IR), and log leptin. For the African women the variance in adiponectin level was explained mostly (and significantly) by IR (HOMA-IR). The variance in adiponectin level of the Caucasian women was mostly (and significantly) explained by triacylglycerol, leptin, and HOMA-IR levels.

When investigating the role of ethnicity in a combined group of African and Caucasian women, significant interaction terms for ethnicity and two other components were found, namely triacylglycerol and leptin levels, i.e. for triacylglycerol, $(F(1217)=$ 67.23; $P<0.001)$; and leptin, $(F(1217)=5.02$; $P=0.026)$. Interaction terms for ethnicity and BMI, adiponectin and IR were found to be non-significant, i.e. for BMI $(F(1217)=0.294 ; P=0.588)$; adiponectin, $(F(1217)=0.421 ; P=0.517) ;$ and for HOMA-IR $(F(1217)=0.05 ; P=0.819)$. Results of a multiple regression analysis with $\log$ adiponectin as the dependent variable, and where ethnicity was included in the independent variable list, are shown in Table 5. Results showed that variation in adiponectin levels was significantly explained by ethnicity, triacylglycerol, leptin, and HOMA-IR.

Table 2 The leptin and adiponectin levels of African and Caucasian women with different levels of obesity (mean \pm s.D. (95\% confidence intervals)).

\begin{tabular}{|c|c|c|c|}
\hline & African women & Caucasian women & $P$ value \\
\hline \multicolumn{4}{|l|}{ Normal weight } \\
\hline$N$ & 38 & 41 & \\
\hline BMI $\left(\mathrm{kg} / \mathrm{m}^{2}\right)$ & $21.8 \pm 1.58(21.3-22.3)$ & $21.6 \pm 1.66(21.0-22.1)$ & 0.503 \\
\hline Adiponectin (ng/ml) & $12.0 \pm 4.62(10.5-13.5)$ & $13.7 \pm 4.21(12.4-15.1)$ & 0.047 \\
\hline Leptin $(\mathrm{ng} / \mathrm{ml})$ & $32.2 \pm 14.0(27.6-36.8)$ & $22.5 \pm 14.6(17.8-27.2)$ & $<0.001$ \\
\hline \multicolumn{4}{|l|}{ Overweight } \\
\hline$N$ & 26 & 31 & \\
\hline BMI $\left(\mathrm{kg} / \mathrm{m}^{2}\right)$ & $27.1 \pm 1.31(26.6-27.6)$ & $27.2 \pm 1.45(26.6-27.7)$ & 0.817 \\
\hline Adiponectin (ng/ml) & $11.5 \pm 5.78(9.01-13.9)$ & $10.3 \pm 3.50(8.98-11.5)$ & 0.648 \\
\hline Leptin (ng/ml) & $57.1 \pm 21.2(48.3-65.8)$ & $45.2 \pm 16.6(39.1-51.2)$ & 0.019 \\
\hline \multicolumn{4}{|l|}{ Obese } \\
\hline$N$ & 38 & 43 & \\
\hline BMI $\left(\mathrm{kg} / \mathrm{m}^{2}\right)$ & $34.8 \pm 4.32(33.4-36.2)$ & $36.0 \pm 5.29(34.4-37.7)$ & 0.249 \\
\hline Adiponectin (ng/ml) & $9.64 \pm 5.52(7.80-11.5)$ & $9.28 \pm 3.79(8.11-10.5)$ & 0.960 \\
\hline Leptin (ng/ml) & $83.4 \pm 25.1(75.1-91.6)$ & $82.7 \pm 26.1(74.7-90.8)$ & 0.895 \\
\hline
\end{tabular}


Table 3 Correlations between fasting (log) adiponectin and variables associated with the metabolic syndrome, for each ethnic group.

\begin{tabular}{lcc}
\hline & $\begin{array}{c}\text { African } \\
\text { women } \\
(N=102)\end{array}$ & $\begin{array}{c}\text { Caucasian } \\
\text { women } \\
(N=115)\end{array}$ \\
\hline Age & $r=-0.25$ & $r=-0.11$ \\
Body mass index & $P=0.015$ & $P=0.214$ \\
Waist circumference & $P=-0.35$ & $r=-0.40$ \\
& $r=-0.47$ & $P<0.001$ \\
Systolic blood pressure & $P<0.001$ & $r=-0.48$ \\
Diastolic blood pressure & $r=-0.14$ & $P<0.001$ \\
& $P=0.169$ & $r=-0.14$ \\
Windkessel compliance & $r=-0.30$ & $P=0.128$ \\
High-density lipoprotein & $P=0.003$ & $P=0.18$ \\
& $r=0.04$ & $r=-0.33$ \\
Log triacylglycerol & $P=0.721$ & $P<0.001$ \\
& $r=0.32$ & $r=0.49$ \\
Log leptin & $P=0.001$ & $P<0.001$ \\
& $r=-0.38$ & $r=-0.56$ \\
Fasting glucose & $P<0.001$ & $P<0.001$ \\
Fasting Insulin & $r=-0.34$ & $r=-0.43$ \\
Fasting C-peptide & $P=0.001$ & $P<0.001$ \\
& $r=-0.43$ & $r=-0.32$ \\
HOMA-IR & $P<0.001$ & $P=0.001$ \\
& $r=-0.41$ & $r=-0.58$ \\
& $P<0.001$ & $P<0.001$ \\
& $r=-0.27$ & $r=-0.55$ \\
& $P<0.01$ & $P<0.001$ \\
HOMA-IR, homeost & $r=-0.56$ \\
& $P=0.008$ & $P<0.001$ \\
& &
\end{tabular}

HOMA-IR, homeostasis model assessment-insulin resistance.

\section{Discussion}

The present study revealed two important findings. First, it confirmed previous findings from AfricanAmerican subjects (15), namely that normal weight African women have marginally lower plasma adiponectin levels than normal weight Caucasian women (12.0 vs $13.7 \mathrm{ng} / \mathrm{ml} ; P=0.047)$. This statistically significant difference, which is also accompanied by increased leptin levels in the African women, seems to disappear as levels of obesity progresses, since there were no differences in adiponectin (or leptin) levels between the obese African and Caucasian women. The sizes of the subject groups, at 38 and 41 , could be questioned, even though a power analysis revealed that 35 subjects would be enough. Nevertheless it is questionable in the first place whether the adiponectin difference in the normal weight groups are truly biologically significant. Values were physiologically in close range and this difference should be interpreted with caution. It is notable that when the whole groups were compared, the adiponectin levels were also similar, even though leptin levels were elevated in the African women.

Secondly, the most prominent finding of this study is that the African women exhibited different associations with adiponectin than the Caucasian women in the multiple regression analysis (Table 4). The adiponectin levels of the Caucasian women showed the strongest associations with IR, leptin, and lipids, which is in line with existing literature $(10,12)$. Both Weyer et al. (10) and Ryan et al. (12) concluded in their studies on Caucasians $(N=126)$ and African-Americans $(N=22)$, and Caucasians $(N=23)$ and Pima Indians $(N=121)$ that the degree of hypoadiponectinemia is more closely related to the degree of IR and hyperinsulinemia than to that of adiposity and glucose intolerance. The results of the present study also confirm this in African women. However, the total variance in adiponectin level of the Caucasian women was also significantly described by other components of the metabolic syndrome, namely triacylglycerol $(\beta=-0.36, P<0.001)$ and leptin $(\beta=-0.28, P<0.026)$. In African women it seems as if only IR plays an important role in its association with adiponectin levels, whereas other components of the metabolic syndrome were not closely associated (as concluded from the various entered independent variables). From this result, it could therefore be argued that possible ethnic differences might exist regarding the functioning of adiponectin within the scope of the metabolic syndrome.

The possibility of ethnic differences was reconfirmed in a final regression analysis (Table 5). Here it is shown clearly that ethnicity (together with the previously listed variables, namely IR, leptin, and triacylglycerol levels) significantly contributes $(\beta=0.17, P=0.017)$ to the variance in adiponectin levels of the combined group of African and Caucasian women. There are probably two

Table 4 Multiple regression analyses with $(\mathrm{log})$ adiponectin level as the dependent variable performed separately for African and Caucasian women.

\begin{tabular}{|c|c|c|c|c|c|c|}
\hline \multirow{2}{*}{$\begin{array}{l}\text { Independent } \\
\text { variables }\end{array}$} & \multicolumn{3}{|c|}{ African women $(N=102) R^{2}=0.25$} & \multicolumn{3}{|c|}{ Caucasian women $(N=115) R^{2}=0.42$} \\
\hline & $\beta$-value & Std. error & $P$ value & $\beta$-value & Std. error & $P$ value \\
\hline Age & -0.10 & 0.097 & 0.301 & 0.11 & 0.079 & 0.187 \\
\hline $\mathrm{BMI}$ & -0.04 & 0.138 & 0.756 & 0.07 & 0.130 & 0.59 \\
\hline Log trig & -0.18 & 0.210 & 0.096 & -0.36 & 0.127 & $<0.001$ \\
\hline Log leptin & -0.05 & 0.134 & 0.711 & -0.28 & 0.063 & 0.026 \\
\hline HOMA-IR & -0.34 & 0.108 & 0.002 & -0.28 & 0.002 & 0.006 \\
\hline
\end{tabular}

Std. error; standard error of $\beta$-value; BMI, body mass index; Log trig, logarithmically transformed triacylglycerol; HOMA-IR, homeostasis model assessmentinsulin resistance. 
Table 5 Multiple regression analyses with (log) adiponectin level as the dependent variable and ethnicity included in the independent variables list $\left(R^{2}=0.34\right)$.

\begin{tabular}{lccc}
\hline $\begin{array}{l}\text { Independent } \\
\text { variables }\end{array}$ & $\beta$-value & Std. error & $\boldsymbol{P}$ value \\
\hline Ethnicity & 0.17 & 0.070 & 0.017 \\
Age & 0.02 & 0.061 & 0.80 \\
Body mass index & 0.03 & 0.093 & 0.78 \\
Log triacylglycerol & -0.32 & 0.075 & $<0.001$ \\
Log leptin & -0.18 & 0.091 & 0.048 \\
HOMA-IR & -0.31 & 0.071 & $<0.001$ \\
\hline
\end{tabular}

Std. error; Standard error of $\beta$-value; HOMA-IR, homeostasis mode assessment-insulin resistance.

main factors that should be considered in an attempt to understand these differences. First, it is possible that certain genetic factors may be involved in determining the relationship and involvement of adiponectin with other components of the metabolic syndrome. It has been reported that adiponectin levels have a genetic heritability of $46 \%$ (26), and genetic polymorphisms in the adiponectin gene were shown to be associated with both obesity and IR (27). Yet, the mechanisms by which adiponectin influences IR, as well as its association with obesity in humans, are unknown. A second factor to be considered is the environment in which the two population groups of this study have developed. In South Africa, the social and physical environment of development of the Caucasian women are usually very similar to those of populations in the Western world, such as Europe or the USA, with abundant availability of the necessary resources. The conditions of most African women, however, are usually characterized by poverty, food insecurity, stunted growth (28), undernutrition in early life, and overnutrition in later life (29-32).

This is not the first study to reveal differences in metabolic syndrome components between the South African Caucasian and African population groups. High prevalences of hypertension (33) have been described in black South Africans compared with Caucasians, with clearly different treatment approaches (34). Africans have low levels of triacylglycerol, and high levels of HDL-cholesterol $(31,35,36)$ compared with Caucasians in South Africa. The results of the present study also show differences regarding body size, namely lower height and body weight in African women. Others have also indicated that the highest levels of obesity in South Africa are amongst urban African women (18, 37). The results of the present study show that the leptin level of the African women (normal and overweight groups) was significantly higher than those of the Caucasian women. In addition, even though correlation coefficients showed negative relationships between leptin and adiponectin in both ethnic groups, the multiple regression analysis which integrates all intercorrelations between independent variables showed associations between leptin and adiponectin only in
Caucasian women (Table 3), thus not in African women. This is an interesting result, especially when it is taken into consideration that the negative slopes ( $\beta$-values) of leptin and IR were similar for the Caucasian women, i.e. contributing to adiponectin variance to the same extent. The African women showed the contrary with a much stronger negative $\beta$-value for IR than leptin levels. This result might indicate that the factors involved in the development and progression of the metabolic syndrome (and ultimately type 2 diabetes) might differ between ethnic groups, whether it is a result of the environment or genetic factors. In addition, this may make possible adiponectin treatment options a challenging endeavor. Nevertheless it is a good indication that adiponectin is negatively associated (in correlations and in multiple regression analysis) with $\mathrm{IR}$, which seems to be at the core of the metabolic syndrome.

The results of the current study emphasize that not only do these groups differ regarding levels of specific hormones or factors associated with the metabolic syndrome, but also regarding the interaction between these variables during the development of the metabolic syndrome and type 2 diabetes. Exactly how the increased levels of adiposity (and leptin) and decreased levels of adiponectin impact on the mechanisms by which the metabolic syndrome and type 2 diabetes arise in the African population remains unclear at this stage.

The limitations of this study are that only data for women are available, as well as the relatively small sizes of the subject groups. Though the subject groups are comparable with other publications on the same topic, larger sample sizes would be even better when similar analyses are being performed. Nevertheless, this is the first study to present results for a sub-Saharan African population group.

To conclude, even though adiponectin levels of African and Caucasian women are similar, it is clear that there are differences in the associations of adiponectin with different aspects of the metabolic syndrome in these two ethnic groups. In African women adiponectin is mostly associated with hyperinsulinemia, whereas adiponectin of Caucasian women is also related to leptin and lipid levels. More experimental studies of the in vitro and in vivo effects of adiponectin on other adipocytokines, insulin signaling, and glucose metabolism are needed within these ethnic groups to establish whether adiponectin has a role as mediator or molecular link between obesity and hyperinsulinemia.

\section{Acknowledgements}

The authors thank the supporting staff and are also grateful for those funding this project, namely the South African National Research Foundation (NRF GUN number 2054068), Medical Research Council and 
Focus Area 9.1 of the NWU, and Dresden University of Technology funding grant MeDDrive.

\section{References}

1 Matsuzawa Y. Adiponectin: Identification, physiology and clinical relevance in metabolic and vascular disease. Atherosclerosis. Supplements 20056 7-14.

2 Okamoto Y, Kihara S, Ouchi N, Nishida M, Arita Y, Kumada M, Ohashi K, Sakai N, Shimomura I, Kobayashi H, Terasaka N, Inaba T, Funahashi T \& Matsuzawa Y. Adiponectin reduces atherosclerosis in apolipoprotein E-deficient mice. Circulation 2002 106 2767-2770.

3 Ouchi N, Kihara S, Arita Y, Nishida M, Matsuyama A, Okamoto Y, Ishigami M, Kuriyama $H$, Kishida K, Nishizawa H, Hotta K, Muraguchi M, Ohmoto Y, Yamashita S, Funahashi T \& Matsuzawa Y. Adipocyte-derived plasma protein, adiponectin, suppresses lipid accumulation and class A scavenger receptor expression in human monocyte-derived macrophages. Circulation 2001103 1057-1063.

4 Stefan N, Stumvoll M, Vozarova B, Weyer C, Funahashi T, Matsuzawa Y, Bogardus C \& Tataranni PA. Plasma adiponectin and endogenous glucose production in humans. Diabetes Care 200326 3315-3319.

5 Yamauchi T, Kamon J, Minokoshi Y, Ito Y, Waki H, Uchida S, Yamashita S, Noda M, Kita S, Ueki K, Eto K, Akanuma Y, Froguel P, Foufelle F, Ferre P, Carling D, Kimura S, Nagai R, Kahn BB \& Kadowaki T. Adiponectin stimulates glucose utilization and fattyacid oxidation by activating AMP-activated protein kinase. Nature Medicine 20028 1288-1295.

6 Maeda N, Shimomura I, Kishida K, Nishizawa H, Matsuda M, Nagaretani H, Furuyama N, Kondo H, Takahashi M, Arita Y, Komuro R, Ouchi N, Kihara S, Tochino Y, Okutomi K, Horie M, Takeda S, Aoyama T, Funahashi T \& Matsuzawa Y. Diet-induced insulin resistance in mice lacking adiponectin/ACRP30. Nature Medicine 20028 731-737.

7 Engeli S, Feldpausch M, Gorzelniak K, Hartwig G, Heintze U, Janke J, Mohlig M, Pfeiffer AFH, Luft FC \& Sharma AM. Association between adiponectin and mediators of inflammation in obese women. Diabetes 200352 942-947.

8 Arita Y, Kihara S, Ouchi N, Takahashi M, Maeda K, Miyagawa J, Hotta K, Shimomura I, Nakamura T, Miyaoka K, Kuriyama H, Nishida M, Yamashita S, Okubo K, Matsubara K, Muraguchi M, Ohmoto Y, Funahashi T \& Matsuzawa Y. Paradoxical decrease of an adipose-specific protein, adiponectin, in obesity. Biochemical and Biophysical Research Communications 1999257 79-83.

9 Hotta K, Funahashi T, Arita Y, Takahashi M, Matsuda M, Okamoto Y, Iwahashi H, Kuriyama H, Ouchi N, Maeda K, Nishida M, Kihara S, Sakai N, Nakajima T, Hasegawa K, Muraguchi M, Ohmoto Y, Nakamura T, Yamashita S, Hanafusa T \& Matsuzawa Y. Plasma concentrations of a novel, adipose-specific protein, adiponectin, in type 2 diabetic patients. Arteriosclerosis, Thrombosis, and Vascular Biology 2000 20 1595-1599.

10 Weyer C, Funahashi T, Tanaka S, Hotta K, Matsuzawa Y, Pratley RE \& Tataranni PA. Hypoadiponectinemia in obesity and type 2 diabetes: close association with insulin resistance and hyperinsulinemia. Journal of Clinical Endocrinology and Metabolism 200186 1930-1935.

$11 \mathrm{Hu}$ E, Liang P \& Spiegelman BM. AdipoQ is a novel adipose-specific gene dysregulated in obesity. Journal of Biological Chemistry 1996 271 10697-10703.

12 Ryan AS, Berman DM, Nicklas BJ, Sinha M, Gingerich RL, Meneilly GS, Egan JM \& Elahi D. Plasma adiponectin and leptin levels, body composition, and glucose utilization in adult women with wide ranges of age and obesity. Diabetes Care 200326 2383-2388.
13 Lindsay RS, Funahashi T, Krakoff J, Matsuzawa Y, Tanaka S, Kobes S, Bennett PH, Tataranni PA, Knowler WC \& Hanson RL. Genome-wide linkage analysis of serum adiponectin in the Pima Indian population. Diabetes 200352 2419-2425.

14 Menzaghi C, Ercolino T, Di PR, Berg AH, Warram JH, Scherer PE, Trischitta V \& Doria A. A haplotype at the adiponectin locus is associated with obesity and other features of the insulin resistance syndrome. Diabetes $2002512306-2312$.

15 Hulver MW, Saleh O, MacDonald KG, Pories WJ \& Barakat HA. Ethnic differences in adiponectin levels. Metabolism 200453 1-3.

16 Opie LH \& Seedat YK. Hypertension in sub-Saharan African populations. Circulation $20051123562-3568$.

17 Joffe BI, Wing JR, Zouvanis M, Pieterse A \& Seftel HC. NIDDM in African-Americans and black South Africans: many similarities but some important differences. Diabetes Care 1996 19 1451-1452.

18 Puoane T, Steyn K, Bradshaw D, Laubscher R, Fourie J, Lambert V \& Mbananga N. Obesity in South Africa: the South African demographic and health survey. Obesity Research 2002 10 1038-1048.

19 Deurenberg P, Andreoli A, Borg P, Kukkonen-Harjula K, de LA, van Marken Lichtenbelt WD, Testolin G, Vigano R \& Vollaard N. The validity of predicted body fat percentage from body mass index and from impedance in samples of five European populations. European Journal of Clinical Nutrition 200155 973-979.

20 Imholz BPM, Wieling W, van Montfrans GA \& Wesseling KH. Fifteen years experience with finger arterial pressure monitoring: assessment of the technology. Cardiovascular Research 199838 605-616.

21 Schutte AE, Huisman HW, van Rooyen JM, Malan NT \& Schutte R. Validation of the Finometer device for measurement of blood pressure in black women. Journal of Human Hypertension 200418 79-84.

22 Wesseling KH, Jansen JR, Settels JJ \& Schreuder JJ. Computation of aortic flow from pressure in humans using a nonlinear, threeelement model. Journal of Applied Physiology 199374 2566-2573.

23 Dart AM \& Kingwell BA. Pulse pressure - a review of mechanisms and clinical relevance. Journal of the American College of Cardiology 200137 975-984.

24 Silke B \& McAuley D. Accuracy and precision of blood pressure determination with the Finapres: an overview using re-sampling statistics. Journal of Human Hypertension 199812 403-409.

25 Langewouters GJ, Settels JJ, Roelandt R \& Wesseling KH. Why use Finapres or Portapres rather than intra-arterial or intermittent non-invasive techniques of blood pressure measurement? Journal of Medical Engineering and Technology 199822 37-43.

26 Comuzzie AG, Funahashi T, Sonnenberg G, Martin LJ, Jacob HJ, Black AEK, Maas D, Takahashi M, Kihara S, Tanaka S, Matsuzawa Y, Blangero J, Cohen D \& Kissebah A. The genetic basis of plasma variation in adiponectin, a global endophenotype for obesity and the metabolic syndrome. Journal of Clinical Endocrinology and Metabolism 200186 4321-4325.

27 Stumvoll M, Tschritter O, Fritsche A, Staiger H, Renn W, Weisser M, Machicao F \& Haring H. Association of the T-G polymorphism in adiponectin (exon 2) with obesity and insulin sensitivity: interaction with family history of type 2 diabetes. Diabetes 200251 37-41.

28 Kruger HS, Margetts BM \& Vorster HH. Evidence for relatively greater subcutaneous fat deposition in stunted girls in the North West Province, South Africa, as compared with non-stunted girls. Nutrition 200420 564-569.

29 Kruger HS, Venter CS, Vorster HH \& Margetts BM. Physical inactivity is the major determinant of obesity in black women in the North West Province, South Africa: the THUSA study. Nutrition 200218 422-427.

30 Kruger HS, Venter CS \& Vorster HH. Obesity in African women in the North West Province, South Africa is associated with an increased risk of non-communicable diseases: the THUSA study. British Journal of Nutrition 200186 733-740. 
31 Oosthuizen W, Vorster HH, Kruger A, Venter CS, Kruger HS \& de Ridder JH. Impact of urbanisation on serum lipid profiles the THUSA survey. South African Medical Journal 200292 $723-728$.

32 Vorster HH, Wissing MP, Venter CS, Kruger HS, Kruger A Malan NT, de Ridder JH, Veldman FJ, Steyn HS, Margetts BM \& MacIntyre U. The impact of urbanization on physical, physiological and mental health of Africans in the North West Province of South Africa: the THUSA study. South African Journal of Science 200096 505-514.

33 Seedat YK. Hypertension in black South Africans. Journal of Human Hypertension 199913 96-103.

34 Brewster LM, van Montfrans GA \& Kleijnen J. Systematic review: antihypertensive drug therapy in black patients. Annals of Internal Medicine 2004141 614-627.
35 Steyn K, Kazenellenbogen JM, Lombard CJ \& Bourne LT. Urbanization and the risk for chronic diseases of lifestyle in the black population of the Cape Peninsula, South Africa. Journal of Cardiovascular Risk 19974 135-142.

36 Oelofse A, Jooste PL, Steyn K, Badenhorst CJ, Lombard C, Bourne L \& Fourie J. The lipid and lipoprotein profile of the urban black South Africa population of the Cape Peninsula - the BRISK study. South African Medical Journal 199686 162-166.

37 Walker AR, Adam F \& Walker BF. World pandemic of obesity: the situation in Southern African populations. Public Health 2001 $115368-372$.

Received 22 January 2007

Accepted 16 May 2007 